\title{
The Rich Get Richer: Enabling Conditions for Knowledge Use in Organizational Work Teams
}

\section{Citation}

Valentine, Melissa, Bradley R. Staats, and Amy C. Edmondson. "The Rich Get Richer: Enabling Conditions for Knowledge Use in Organizational Work Teams." Harvard Business School Working Paper, No. 13-001, July 2012.

\section{Permanent link}

http://nrs.harvard.edu/urn-3:HUL.InstRepos:9055162

\section{Terms of Use}

This article was downloaded from Harvard University's DASH repository, and is made available under the terms and conditions applicable to Other Posted Material, as set forth at http:// nrs.harvard.edu/urn-3:HUL.InstRepos:dash.current.terms-of-use\#LAA

\section{Share Your Story}

The Harvard community has made this article openly available.

Please share how this access benefits you. Submit a story.

Accessibility 

H A R V A R D
B U S I N E S S
S C H O O L

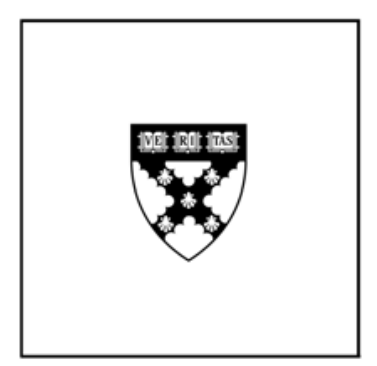

\title{
Competing Effects of Individual and Team Experience on Knowledge Sourcing Behavior
}

\author{
Melissa A. Valentine \\ Bradley R. Staats \\ Amy C. Edmondson
}

\section{Working Paper}

13-001

August 4, 2014 


\title{
Competing effects of individual and team experience on knowledge sourcing behavior
}

\begin{abstract}
This paper develops and tests a multi-level model that links individual and team experience with knowledge sourcing (specifically, knowledge repository (KR) use). Prior research theorizes that experienced workers source more than inexperienced workers because they have stronger information processing capabilities that motivate their search. Other research, however, suggests that teams source less as they gain experience because they develop and perpetuate set ways of thinking about problems. Which effect dominates the sourcing behavior of individuals working in teams? We argue that individual knowledge-sourcing behavior is shaped by both individual and team attributes and we provide an empirical test of new theory. Specifically we suggest that both individual capabilities and team average experience influence team member knowledge sourcing, and argue that there is an interaction between individual and team experience (meaning rookies and veterans working on inexperienced or experienced teams will be influenced differently). We find empirical support for this model. Team experience does not affect veteran team member knowledge sourcing, unless the team is very experienced; then, veterans slow their KR use. Rookies are more influenced by team composition: when working on teams with too little experience, too much experience, or a disparity of experience, rookie KR sourcing is limited. Yet on moderately experienced teams, rookies use almost on par with veterans. Importantly, limited KR use by highly experienced teams does not appear to be a savvy choice for exploiting team resources: KR use predicts team performance and the effect is not moderated by team experience.
\end{abstract}

Key Words: Knowledge Sourcing, Team Experience, Team Performance, Multilevel

\section{Introduction}

Knowledge workers need particular skills, practices and understanding to accomplish their work.

Traditionally, they gain this knowledge through formal university training followed by domain-specific

knowledge acquisition "on the job" through learning-by-doing and mentorship from co-workers.

However, globalization has dramatically changed this traditional skill acquisition paradigm (Clark,

Huckman, Staats; 2013). Global firms in developing markets have grown rapidly (as an example, the ITenabled services industry in India employs over three million people today, compared to fewer than 700,000 in 2003 (Khanna, 2013)), and employ large numbers of people early in their careers who have limited personal experience to rely upon in their daily work (Levenson, 2012; Ready, Hill, \& Conger, 2008). Even when experienced workers are present within a firm, inexperienced workers tend to be poorly connected in organizational knowledge sharing networks, such that they cannot easily find 
knowledgeable colleagues for help (Singh, Hansen, \& Podolny, 2010). Global firms thus face a problem: their inexperienced workers need organizational knowledge to do their work but are unlikely to have the experience or the personal relationships that easily provide "how-to" knowledge.

One approach commonly used to address this challenge involves an electronic knowledge repository (KR). A KR offers a practical solution to help people gain access to the "how-to" knowledge they would otherwise lack (Davenport \& Prusak, 1998; Stein \& Zwass, 1995). However, a knowledge repository cannot provide needed knowledge to inexperienced workers unless they use it (an activity sometimes referred to as knowledge sourcing (Gray \& Meister, 2004)). Prior research suggests that inexperienced people may not use a KR without intervention. People use information channels when they expect to derive valuable information from doing so (Carlson \& Zmud, 1999). Although inexperienced workers would benefit from knowing the information that is immediately and constantly available in the KR, they may not know how to effectively search the KR and identify relevant information (Markus, 2001; Sutcliffe, Ennis, \& Watkinson, 2000). Veteran workers have stronger information processing capabilities because of their experience at the firm, so they are more likely to expect that KR use will yield valuable information (Bock, Zmud, Kim, \& Lee, 2005; Carlson \& Zmud, 1999). Thus, although a KR seems to offer a practical solution for providing knowledge to inexperienced workers, it may not work if they lack the knowledge-base needed to support KR sourcing.

Prior research thus suggests that individual inexperience constrains knowledge sourcing. Yet knowledge workers frequently complete their work in project teams, and other research has shown that individuals' behavior is strongly influenced by their team, not just by their own attributes (Hackman, 1992; Mathieu, Maynard, Rapp, \& Gilson, 2008). Inexperienced workers' information processing capabilities and sourcing activities may be enabled by participation in a team. Teams are composed of people with varying degrees of experience and familiarity. Working on a team with high experience or familiarity may enrich individual team members' abilities, either directly or indirectly. For example, strong team members directly train teammates whom they perceive to have lower abilities (Jackson \& LePine, 2003). And teams implicitly influence their less experienced members through example or 
exposure to expert mental models (Hackman, 1992). Moreover, when placed in a team, inexperienced workers may be able to identify experienced colleagues more easily than within the firm more broadly (Griffith \& Neale, 2001; Singh et al., 2010; Zhang, Hempel, Han, \& Tjosvold, 2007). Therefore, in the present research we explore whether inexperienced workers' teams influence their knowledge sourcing. Exploring this question, we encounter conflicting and incomplete perspectives in the literature about the relationship between team experience and rookie team member knowledge sourcing. Individuals source more as they gain experience, but teams actually source less as they gain experience (both when measured as average firm experience and shared team experience, sometimes referred to as team familiarity). Experienced or familiar teams develop and perpetuate set ways of thinking about and solving problems (O'Reilly, Caldwell, \& Barnett, 1989; Rentsch \& Klimoski, 2001). This stasis means that experienced teams become less likely to source knowledge, in part to avoid new ideas or best practices that might conflict with existing shared mental models or practices (Katz, 1982; Katz \& Allen, 1982). Eventually their performance may suffer (Katz, 1982; Berman et al. 2002). Considered together, this prior research presents a tension between individual and team experience: inexperienced people may have too little personal experience to source knowledge effectively and therefore need an experienced team to help them source external knowledge, but experienced teams may not actually want additional, external knowledge. Which effect dominates the sourcing behavior of individuals working in teams?

The present research seeks to resolve this tension with an empirical test of new theory. We develop a multi-level model of knowledge sourcing that integrates research on individual information processing and research on team composition (experience, familiarity, and disparity in experience) to explain how team-level experience supports or inhibits individual knowledge sourcing. We propose a cross-level moderation effect between team composition and individual experience. Specifically, we propose that high levels of team experience (either average years at the firm or team familiarity) help inexperienced workers source but may inhibit sourcing among experienced team members. We also propose that the relative distribution of team experience among team members affects rookies and veteran team members differently. We hypothesize that due to status effects and specialization, experienced team 
members source more when they are especially senior compared their teammates, and inexperienced team members source less when they are especially junior compared to their teammates. We predict that the broadest sourcing patterns are likely at moderate levels of team experience and familiarity, because moderate team experience supports inexperienced team members to source needed knowledge but does not establish the homogenizing or inertial dynamics that inhibit sourcing by veteran teams.

We test our model using unique and detailed archival data on knowledge sourcing from a KR at Wipro Technologies, an India-based, but globally active, outsourced provider of software services. These data report KR use on a per-click basis for over 9,000 individuals in more than 300 software project development teams. To test our research questions we linked these data with other Wipro databases reporting individual and team properties and performance.

To begin, our baseline results confirm those found in prior research. Inexperienced individuals source less than experienced individuals in every condition - consistent with theory that suggests that rookies do not have the information processing capabilities needed to expect to derive valuable knowledge from a KR. We also find that team experience and familiarity both have an inverted-U shaped relationship with team member sourcing, so that very high team experience and familiarity are associated with less team member sourcing than moderate team experience or familiarity, on average.

Our multi-level model reveals that the pattern underlying these results is a cross-level moderation effect between individual experience and team experience. In particular, our results show that rookies source little from the KR when their team is inexperienced. Notably, at moderate levels of team experience, rookies source almost as much as veterans, suggesting that team experience can help mitigate the challenges of limited personal experience. But, at high levels of team experience, both rookies and veterans source less from the KR, with the sharpest decline among experienced team members. In short, some team experience supports KR use by inexperienced team members (helping overcome their limited individual capabilities), but too much team experience leads them to stop seeking outside ideas. Further, we find that veteran team members source more when their experience level is higher than most of their team and inexperienced team members source less when they are especially junior compared to their team 
mates. We do not find a cross-level moderation effect for team familiarity: all team members source more on familiar teams, but slow use on very familiar teams.

Importantly, limited KR use by highly experienced or familiar teams does not appear to be a savvy choice for exploiting team resources. KR use predicts team performance on average and the effect is not moderated for experienced or inexperienced teams. In summary, team and individual experience both influence KR use. Too little or too much team experience inhibits use, but for different members of the team. We discuss implications of these findings for theory and practice.

\section{Individual Experience, Team Composition, KR Sourcing, and Performance}

We develop a multi-level model that integrates research on individual- and team-level factors that affect individual knowledge sourcing and propose a cross-level moderation effect. A cross-level moderation effect means that the team-level factors (team average experience and team familiarity) differentially influence inexperienced and experienced workers (Kozlowski \& Klein, 2000). In so doing, we seek to reconcile the tension between research on individual inexperience and knowledge sourcing (which suggests that individual experience leads to more knowledge sourcing) and team experience and knowledge sourcing (which suggests that team experience leads to less knowledge sourcing).

Our multi-level theory focuses on individual and team firm experience. Prior research conceptualizes human capital as formal educational achievement, firm-specific experience (e.g., years at a given firm), industry-specific experience (e.g., years working in an industry), or total years spent working. We focus specifically on the effects of firm experience because much information processing and many related knowledge structures are firm-specific (Grant, 1996; Nonaka, 1994; Reagans, Argote, \& Brooks, 2005; Spender, 1996). For example, Huckman and Pisano (2006) showed surgeon performance improved with increasing hospital-specific experience, but not procedure-specific experience gained at other hospitals (see also, Kc and Staats (2012)). (Of course, general information processing capabilities also improve with work experience so we control for prior experience in our empirical model.)

\subsection{Individual Firm Experience and Individual Knowledge Sourcing}

First, we theorize the relationship between individual firm experience and knowledge sourcing. 
We propose that people with high firm experience engage in more knowledge sourcing than their inexperienced peers. People learn as they perform tasks in their firm, and this on-going experiential learning helps them understand their tasks better, understand relationships between variables related to the task more clearly, and better adapt existing knowledge to new and different tasks (Bohn, 2005; Dutton \& Thomas, 1984; Huber, 1991). As individuals spend more time working at their firm, they become more sophisticated and skilled at interpreting and synthesizing organizational information that is both closely and distantly related to their tasks. Thus their experience at their firm improves their related information processing capabilities. ${ }^{1}$ The more that people understand their work, and the broader work of the organization, the more likely they are to expect that they will access valuable information through KR sourcing (Carlson \& Zmud, 1999). Also, organizational tenure and related technical knowledge produce positive beliefs about information technology and subsequent adoption of the technology (Agarwal \& Prasad, 2000).

In contrast, inexperienced individuals may be struggling with questions like "What does this mean?" or "How does this relate to that?" and not know how to pose a specific question in the technical language of the organization (Gray \& Durcikova, 2005). KR use is most effective when prompted by a well-developed question about how to do something specific (Markus, 2001). Without an expectation that sourcing will produce valuable knowledge, rookie members of the firm may be inhibited or demotivated to source (Bock et al., 2005; Carlson \& Zmud, 1999; Fishbein \& Ajzen, 1975; Vroom, 1964). Also, inexperienced individuals may experience increased cognitive complexity and cognitive load when trying to make sense of new problems and new channels for accessing knowledge and be overloaded by the prospect of a KR system (Borycki, Lemieux-Charles, Nagle, \& Eysenbach, 2009).

In summary, we argue that individuals with more firm experience will have a greater understanding and appreciation of their work and how the knowledge stored in a KR relates to their work.

\footnotetext{
${ }^{1}$ The term "information processing" originated in communications research and was adapted by organizational theorists to describe organizational and group processes for identifying, analyzing, interpreting and synthesizing information (Driver \& Streufert, 1969; Galbraith, 1974; Hinsz et al., 1997; Shannon \& Weaver, 1971; Tushman \& Nadler, 1978).
} 
Inexperienced people may be less likely to expect to derive value from KR sourcing and less likely to source than experienced workers (Bock, Sabherwal, \& Qian, 2008; Fishbein \& Ajzen, 1975; Vroom, 1964; Watson \& Hewett, 2006). Thus we hypothesize:

HYPOTHESIS 1: Individual firm experience has a positive relationship with individual KR sourcing.

\subsection{Team Composition and Team Member Knowledge Sourcing}

Next, we theorize the effects of team composition (team average firm experience and team familiarity) on individual team member knowledge sourcing. Teams are collections of individuals, but as social entities, they also develop and perpetuate group-level properties, capabilities, and behaviors that cannot be understood simply as the aggregate characteristics and abilities of team members (Hargadon \& Bechky, 2006; Larson, 2010; Woolley, Chabris, Pentland, Hashmi, \& Malone, 2010). Team average experience and team familiarity are team-level properties resulting from how the team is composed, and both give rise to group-level dynamics related to team member KR use.

Both experienced and familiar teams have strong aggregate information processing capabilities which can support team member KR use. Experience at the firm and experience working together establish shared mental models, shared language, effective information sharing, and effective coordination of expertise (Alge, Wiethoff, \& Klein, 2003; Hofmann, Lei, \& Grant, 2009; Huber \& Lewis, 2011; Lewis, Lange, \& Gillis, 2005; Salas, Cooke, \& Rosen, 2008). On experienced teams, team members participate in or are exposed to expert discussions that help define and articulate specific problems (Hackman, 1992). On familiar teams, team members are more likely to have a shared understanding of task requirements, to know who knows what within the team, and to be able to use this knowledge to coordinate their activities (Balkundi \& Harrison, 2006; Gino, Argote, Miron-Spektor, \& Todorova, 2010; Lewis et al., 2005; Staats, 2012; Wegner, 1987).

The information processing capabilities of experienced or familiar teams enable the critical processes of articulating specific work problems and anticipating and identifying useful information in the KR (Markus, 2001). Individuals on experienced teams may also be better supported in applying 
information obtained from the KR than people on inexperienced teams and may find increasing motivation for use because of this achieved value (Bock, Sabherwal, \& Qian, 2008; Fishbein \& Ajzen, 1975; Vroom, 1964; Watson \& Hewett, 2006).

Although team experience and team familiarity may be beneficial, up to a point, there is the risk that too much of either one may prove detrimental for individual knowledge sourcing. Both team average experience and team familiarity give rise to social dynamics beyond the aggregate information processing capabilities of the group. High team experience contributes to people thinking alike (O'Reilly et al., 1989; Rentsch \& Klimoski, 2001) and to discussions focused on commonly held rather than uniquely held information (Kim, 1997). Groups' familiarity leads to "behavioral stability, selective exposure, and group homogeneity, which combine to reduce the group's willingness" to search out new (possibly conflicting) knowledge (Berman, Down, \& Hill, 2002; Katz, 1982, pg. 99). Also, longer average firm tenure similarly makes a team less willing to seek out new ideas (Katz 1982). Teams with extensive experience working together and at their firm stop searching for new ideas and information outside of their team (Chi, Huang, \& Lin, 2009; Katz, 1982; Katz \& Allen, 1982; Katz \& Tushman, 1979). These group-level dynamics may inhibit KR use among teams even with strong information processing capabilities. Thus, we hypothesize:

HYPOTHESIS 2a: $\quad$ Team firm experience has a curvilinear relationship with individual KR sourcing.

HYPOTHESIS 2b: Team familiarity has a curvilinear relationship with individual KR sourcing.

\subsection{Cross-level Effects of Individual Experience and Team Composition on Knowledge Sourcing}

Next, we propose cross-level effects of individual firm experience and team composition on team member knowledge sourcing. Cross-level moderator models suggest that "variables at two different levels of analysis (e.g., one group-level variable and one individual-level variable) interact to predict an outcome at the lower level of analysis" (Klein \& Kozlowski, 2000, pg. 219). Specifically, we argue that 
team experience and team familiarity will influence inexperienced and experienced team members' KR use differently.

We first consider how rookies and veteran team members are influenced by inexperienced teams. When teams have low average organizational tenure, most team members have limited personal experience or relevant knowledge. Experienced teammates have already developed the experientialknowledge base necessary to support frequent KR sourcing, so they can source knowledge even in the absence of strong team support. In contrast, inexperienced team members must rely on their own capabilities which may not be strong enough to support KR use (Carlson \& Zmud, 1999; Markus, 2001).

We next consider how rookies and veteran team members are influenced by experienced teams and suggest that rookies are differentially helped (compared with experienced team members) when working on experienced teams. Inexperienced team members on experienced teams can get direct help and exposure to expert ways of thinking about things, which may improve their information processing capabilities so that they are capable and motivated to source more. Inexperienced workers face some risk of feeling inhibited on experienced teams because they may feel the need to get permission to seek or generate new ideas (Gilson, Lim, Luciano, \& Choi, 2013) or may feel that more attention goes to expert team members (Van der Vegt, Bunderson, \& Oosterhof, 2006), but some studies suggest that inexperienced team members benefit from working on experienced teams, through direct or indirect pathways (Hackman, 1992). When team members are perceived to have a low level of ability, experienced team members are more likely to train them directly or work to compensate for their inexperience (Jackson \& LePine, 2003). When people are relatively inexperienced compared to colleagues, those colleagues share more information with them (Rollag, 2004). Experienced people generally engage in extra-role helping behaviors, like helping inexperienced teammates ( $\mathrm{Ng} \&$ Feldman, 2010). The direct help may include training on the KR or may improve information processing capabilities to support use, like helping articulate a problem in a way that facilitates KR use. Inexperienced team members also receive indirect help. Experienced teams expose inexperienced team members to high-level, expert conversations (Hackman, 1992). 
Veteran workers are likely to have a different experience when working on an experienced team. Veterans on experienced teams are likely to have converging perspectives, so they may feel that there is nothing more they need to learn and so might source less. Experienced people converge more in their thinking about tasks than less experienced individuals (Rentsch, Heffner, \& Duffy, 1994). Also, experts emphasize shared knowledge more than non-experts (Thomas-Hunt, Ogden, \& Neale, 2003).

Experienced team members on experienced teams are likely to have convergent mental models, and are less likely to see a need for outside knowledge.

Together these mechanisms suggest different relationships between team experience and individual experience and support the following hypothesis:

HYPOTHESIS 3a: Team firm experience will moderate the relationship between individual firm experience and KR sourcing such that inexperienced team members will source more as average team experience increases and experienced team members will source less at high level levels of team experience.

We propose the same basic pattern for inexperienced and experienced people working on familiar teams, but with different mechanisms. On teams with low familiarity, rookies may struggle to get help from their teammates. Unfamiliar teams may provide less information and help-giving (Huckman, Staats, \& Upton, 2009; Okhuysen, 2001). Veteran teammates already have stronger expectations that their sourcing will be valuable based on their own information processing capabilities. On teams with high familiarity, the relational ties between rookies and their teammates will be stronger, facilitating better knowledge flow and transfer (Huckman et al., 2009; Lewis et al., 2005). Better information flow may yield the sourcing benefits articulated above.

However, very high familiarity may prove problematic for experienced individuals. On familiar teams, relational ties between veterans and teammates will be stronger and may contribute to behavioral stability (Katz, 1982). Experienced people on familiar teams may be particularly invested in a set and familiar way of approaching problems (Rentsch et al., 1994; Rentsch \& Klimoski, 2001). They may maintain status by offering their own known answers rather than admitting that better ideas might exist 
elsewhere (Thomas-Hunt et al., 2003). Thus, we hypothesize:

HYPOTHESIS 3b: Team familiarity will moderate the relationship between individual firm experience and KR sourcing such that inexperienced team members will source more as team familiarity increases and experienced team members will source less at high level levels of team familiarity

To this point we have focused on the moderating effects of average team experience and team familiarity, which are both team properties based on averages. Yet in building multi-level models, the distribution of individual inputs (i.e., not simply the average) is also important to consider (Harrison \& Klein, 2007; Klein et al., 2000; Klein, Conn, Smith, \& Sorra, 2001). We also consider whether disparity in individual experience across the team differentially influences KR use by rookies and veteran team members. ${ }^{2}$ Two different social dynamics are likely to occur on teams with disparate experience, both of which we interpret to suggest that veterans will source more and rookies will source less.

The first social dynamic relates to the status implications of the disparity. Inexperienced team members may identify as low-status and may avoid behaviors that might seem too proactive because they may not feel that they have permission to seek resources for themselves or for the team (Keltner, Gruenfeld, \& Anderson, 2003). Lower status team members can be distracted by the dynamics of the hierarchy, whereas experienced and higher status team members focus on more goal-directed work (Guinote, 2007; Overbeck \& Park, 2006; Smith, Jostmann, Galinsky, \& van Dijk, 2008). A high-status veteran team member might recognize a knowledge gap and feel empowered to immediately search for the answer, whereas an inexperienced person might be concerned about overstepping and not proactively search the KR. Second (and relatedly), experienced individuals may take on the role of a gatekeeper for the team (Tushman \& Katz, 1980a), sourcing on behalf of inexperienced coworkers. This may be an efficient team strategy because those who are most skilled at KR use can do it effectively on behalf of the team. The resulting pattern would be high levels of KR use for experienced individuals and low levels of

\footnotetext{
${ }^{2}$ We do not hypothesize a direct effect of disparate team experience on individual knowledge sourcing because the theorizing is redundant with the moderation hypothesis. We do control for the direct effect in the empirical model.
} 
use for inexperienced team members when disparity of team experience is high. Thus we hypothesize:

HYPOTHESIS 3c: Disparity of team experience will moderate the relationship between individual firm experience and KR sourcing such that inexperienced team members will source less as disparity of team experience increases and experienced team members will source more as disparity of team experience increases.

\subsection{Team Sourcing, Team Experience and Team Performance}

Finally, we hypothesize a positive relationship between team KR sourcing and team performance. Teams learn and thrive when team members look outside the team for new ideas and inspiration. Teams learn when their members "go out and learn all they possibly can from... other parts of the organization" (Edmondson, 1999, pg. 383). Team members who "collect information/ideas from individuals outside of the team" add to the team's expertise and understanding (Ancona \& Caldwell, 1992, pg. 641). And most relevant to this paper, teams whose members actively consult documents in the firm's electronic databases achieve more efficient performance (Haas \& Hansen, 2007). KR use has been shown to improve team efficiency for the simple reason that KR use allows for knowledge reuse (Haas \& Hansen, 2007). When relevant and high-quality codified knowledge is applied in a new project, it can dramatically reduce the time spent solving task-related problems (Cohen \& Levinthal, 1990; Kogut \& Zander, 1992). Teams can work more efficiently by implementing best practices or reusing knowledge components developed by other teams (Haas \& Hansen, 2007; March \& Simon, 1993). Therefore, consistent with previous research, we hypothesize a positive relationship between KR use and team efficiency performance.

HYPOTHESIS 4: $\quad$ Team KR sourcing is associated with better team performance.

\section{Setting and Data}

\subsection{Setting}


We test our hypotheses in the setting of Wipro Technologies, a company operating in the software services industry. Wipro delivers software system development projects to a global customer base. Software development projects involve implementing new software programs within existing firms by establishing customer requirements, creating adapted solutions for these specific requirements, writing the software code to create the solution and then testing the final product (Boehm, 1981). Team members rely on access to knowledge to successfully complete their projects (Faraj \& Sproull, 2000; Huckman et al., 2009), making this an ideal setting for investigating our hypotheses.

We received data from Wipro on all software development projects that occurred in 2008 and 2009. This time period was marked by significant competition from other software services firms (e.g., Accenture, IBM, TCS and Infosys) and Wipro senior management felt that their continued success depended on delivering projects both efficiently and effectively. To accomplish these goals, management focused on capturing and providing access to previously generated organizational knowledge. The company had established a knowledge management initiative many years before, but in 2007 Wipro launched a new effort to enhance this initiative and invested substantial time and financial resources. Wipro enhanced the interface used for knowledge management (called KNet) and implemented analytic technology to enable the tracking of person-level use of the KR.

All employees could download content from the KR, and were also encouraged to submit content. Submitted content was evaluated and solicited by a knowledge management team in order to maintain the intended quality standards of the system (the team functioned like the knowledge intermediaries described by Markus (2001)). Wipro did not dictate a specific policy on KR sourcing during the study period and all employees received similar messaging about the system by email. The KNet portal resided on the Wipro intranet and was accessible by all employees. After reaching the KNet page, employees saw links to knowledge on different topics (e.g., Java, .Net, or SAP), as well as a box to enter search terms. By entering keywords or phrases an employee could source knowledge related to their particular query. The content of the KR included a limited amount of reusable software, but mainly consisted of documents detailing how the author of the document accomplished a specific task. For example, one knowledge 
artifact explained how an individual implemented mechanisms to lock a database in Sybase (Sybase provides database software and locking the database prevents different individuals from simultaneously entering data which creates a conflict). Another artifact provided an overview of how to use \$AVRS (a tool that allows a system administrator to quickly examine system information online). The knowledge artifacts within Wipro's system are specific to Wipro's context and work processes, but the general process of knowledge sourcing that takes place through KNet is generalizable to many other organizations, and Wipro's approach to knowledge management resembles that of many other organizations (Davenport \& Prusak, 1998; Hansen, Nohria, \& Tierney, 1999).

\subsection{Data}

We used archival data that captured individual KR sourcing and information about individual and team characteristics. The KR data captured how many unique downloads each individual completed on a given day between January 1, 2008 and December 31, 2009. Wipro did not record an identifier for the knowledge artifact viewed. We matched the above data with demographic data on all of the individuals that worked on software development team projects (discussed more below). Our final dataset included information on the 481 software development projects that were started and completed during the study period, meaning we had comprehensive KR sourcing data for the entirety of each project's lifetime.

Table 2 provides summary statistics for study variables.

We note a few additional descriptive statistics. $45 \%$ of the individuals on software development teams had worked at Wipro for less than a year, and $75 \%$ had less than a year of prior work experience. Firm experience and prior experience were correlated at 0.75 .

\subsubsection{Dependent Variables.}

We use two different dependent variables in our models. First, we examine knowledge sourcing by team members. Then we explore how this use affects team performance. The variables used are:

Individual KR Sourcing. The first outcome variable, individual KR sourcing, was calculated as

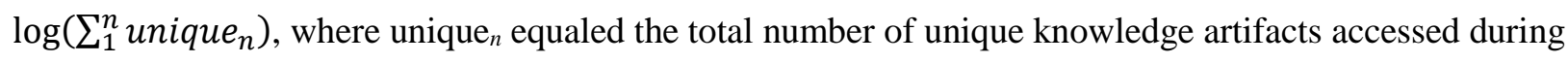
a day and $\mathrm{n}$ denoted each day during the duration of the project. 
Team Performance. We evaluated project performance by investigating the efficiency of the project. Prior literature suggests that team knowledge use will be related to improved project efficiency (Haas \& Hansen, 2007). To capture project efficiency in our setting we created a variable, effort deviation, that compares a project's actual total hours of work to its expected hours of work (in person hours) -

$\frac{\text { Actual Effort-Estimated Effort }}{\text { Estimated Effort }}$. We divided by estimated effort to normalize the measure based on the size of the project. We used the final estimates to construct this measure as these captured the final project requirements. At Wipro, the starting effort estimates are created by sales and pre-sales personnel, however the estimates may change while a project is being executed, typically because the customer changes scope. Wipro has a formal process for managing such changes, in order to make sure that estimates are not adjusted inappropriately, for example because a project has fallen behind its schedule. The change process requires signoff from both the customer and Wipro management. The mean for team performance is -5.2 with a standard deviation of 10.9. This implies that, on average, software projects use slightly less (about 5\%) hours than estimated.

\subsubsection{Independent Variables.}

Individual Firm Experience and Team Firm Experience. Firm experience can be measured in terms of the cumulative number of task performances (Boh, Slaughter, \& Espinosa, 2007; Reagans et al., 2005) or, when appropriate, in terms of organizational tenure as a proxy for number of task performances (Gardner, Gino, \& Staats, 2012; Hitt, Bierman, Uhlenbruck, \& Shimizu, 2006; Huckman \& Pisano, 2006). We constructed a variable, individual firm experience, which captures the number of years an individual worked at Wipro prior to the start of the project. We assessed team firm experience by averaging the individual experience variable across all members on the team.

Team Familiarity. Project team members typically worked on one project at any given time and each team member was reassigned to new projects when the original project was completed. Team members also had different amounts of firm tenure. These dynamics created variability in the prior interactions between team members. Our measure of this shared experience is consistent with prior work (Espinosa, 
Slaughter, Kraut, \& Herbsleb, 2007; Huckman et al., 2009; Reagans et al., 2005). We summed the count of the number of projects that each unique dyad on the team completed together during the previous three years. Using a window of three years accounted for the potential decay of knowledge over time (e.g., Argote, Beckman, \& Epple, 1990). The average project lasted for about seven months, so a three-year window also matches the empirical context, and allowed us to include multiple cycles of projects. We then divided the sum by the total unique dyads within the team to generate our variable, team familiarity (Reagans et al. 2005). We also controlled for an individual's familiarity with teammates by summing the number of projects that an individual completed with every other team member, during the previous three years, and then dividing by the number of team members minus one to scale the variable.

Disparity in Team Firm Experience. We measured the disparity in firm experience across team members. We used the Herfindahl measure, a commonly used approach to measure the construct (Harrison \& Klein, 2007; Narayanan, Balasubramanian, \& Swaminathan, 2009; Staats \& Gino, 2012). The Herfindahl measure takes each individuals' share of the total team experience (i.e., individual i's experience divided by the sum of the team's experience), squares the value, and then sums these values across the team. A team with completely equal experience across individuals would have a low value with this measure. A team with high disparity in experience could have a value approaching one.

\subsubsection{Control Variables.}

We controlled for individual and team variables possibly associated with individual KR sourcing. Individual Prior Work Experience. We included a variable that reported the number of years an individual had been employed prior to working at Wipro.

Project Scale. We controlled for the scale of the project because complex projects may result in more KR use. To capture project scale we used the kilolines of new source code (KLOC) written (MacCormack, Verganti, \& Iansiti, 2001). Prior work has found that software may exhibit scale effects (Banker \& Kemerer, 1989) and so we logged the variable in our models.

Estimated Effort and Duration. Projects that involve either more hours of effort or days of work may be more difficult and so require greater use of the knowledge repository. To control for both of these 
potential effects we included the log of the estimated total person-hours and the log of the estimated total days. We use the estimate in both cases since a project that is over its effort budget or delivered late would have larger actual values than a project that successfully delivers on its estimates.

Team size. We also controlled for the size of the team by counting the number of members who worked on the team and taking the $\log$ of that value.

Offshore Percentage. We controlled for team member location by calculating the percentage of hours that were completed by the team at the Indian facilities and dividing this value by the total number of hours worked by the team. Repeating the analyses with a variable calculated using the number of team members in each location, instead of the hours, generates the same pattern of results as those we report (we provided an Appendix reporting this analysis for our reviewers).

Contract Type. Wipro used either a fixed-price contract structure or a time-and-materials contract structure for its development projects. In the former, the payment was agreed prior to the start of the project, while in the latter Wipro received a pre-specified rate for the hours that they worked on the project. Given the role of incentives in individual and team performance we controlled for contract type. We included an indicator variable in our models that was set to one if the project was fixed price and was zero for time-and-materials.

Software languages: number and type. Different software languages may have different knowledge demands leading to different patterns of KR sourcing. Similarly, projects with multiple software languages (53\% of projects) may have greater knowledge demands and lead to more KR sourcing. We controlled for the former by including indicator variables for the different languages used. We controlled for the latter with an indicator equal to one if a project had more than one software language.

Technologies. Projects that used multiple classes of technologies (e.g., client server, e-commerce) could lead to more KR sourcing. Thus, we created an indicator that equals one if a project had more than one technology (10\% of projects) and was zero otherwise (90\% of projects). 


\section{Results}

Our study contains data at three levels, the individual, the team project, and the customer account. That is, individuals were nested in projects (teams), and projects were nested in customer accounts. We include the nesting of projects within customer accounts because most Indian software service providers, including Wipro, organize their customer facing operations into offshore development centers. These centers provide focused resources that serve a given customer. Although individuals may move between customers, over time, they typically execute multiple projects for a given customer, prior to moving on. We note that if we drop the nesting of projects within customers then we see the same pattern of results for our hypotheses (we provided an Appendix for our reviewers detailing these results). All independent variables were centered and all regressions are estimated with a multi-level, mixed effects linear regression model, using maximum likelihood estimation (Stata command: xtmixed (StataCorp, 2013)).

Table 2 reports the results from our multilevel regression analysis of individual KR sourcing. Column 1 shows the model without the independent variables. Consistent with prior findings in the knowledge sourcing literature (Gray \& Meister, 2004), we find that individuals executing more demanding work (as captured by the kilolines of new code written, a common measure of complexity for a project $)$ are more likely to source knowledge $\left(\beta_{\text {Project Scale }}=0.1564, \mathrm{p}<0.01\right)$. In Column 2 , we add the independent variables to the model. Hypothesis 1 predicted that individual firm experience would be positively associated with KR sourcing, and we find support for this hypothesis: the coefficient on individual experience is positive and significant (Column 2, $\left.\beta_{\text {Individual Firm Exp }}=0.1418, p<0.001\right)$. A one standard deviation increase in individual firm experience is related to $30.3 \%$ more use than the average amount of KR sourcing. Hypothesis 2 predicts that both team firm experience and team familiarity will have a curvilinear relationship on individual knowledge sourcing. Examining both the linear and quadratic terms for team firm experience and team familiarity we find support for this hypothesis.

In Column 3, we add the interactions terms to the model. Hypotheses $3 \mathrm{a}, 3 \mathrm{~b}$, and $3 \mathrm{c}$ each predicted a moderation effect on the relationship between individual firm experience and individual KR 
sourcing through team firm experience, team familiarity and disparity in team firm experience, respectively. We find support for Hypothesis $3 \mathrm{a}$ as the interaction coefficient on individual firm experience and team firm experience is negative and statistically significant. Figure 2a plots the relationship. As hypothesized, at low levels of team experience, experienced team members source significantly more knowledge than rookie team members. However, on highly experienced teams, the rookie team members actually source more knowledge than do experienced team members. On very experienced teams, both rookie and veteran team members significantly slow their KR sourcing.

Moving to Hypothesis 3b, we fail to see support for a moderation effect of team familiarity on the relationship between individual firm experience and individual KR sourcing. This finding shows that the overall effect of team familiarity on individual firm experience is not differentiated for inexperienced or experienced team members. Finally, for Hypothesis 3c, we see partial support for the moderating effect of disparity in firm experience. The coefficient on the interaction term is significant at a $p=0.054$ and Figure 2c plots the relationship for high and low levels of each variable. As predicted, inexperienced individuals source more knowledge when they are on teams with less disparity in experience than when they are on teams with more disparity in experience while the opposite holds true for experienced individuals.

Table 3 reports results from the team performance regression. Team KR sourcing is associated with more efficient team performance, as hypothesized. Team familiarity, but not team experience, also predicts performance. Interaction terms between team familiarity and team KR sourcing, and team experience and team KR sourcing are not significantly related to performance (results not shown).

\section{Discussion and Conclusion}

This research develops and tests a multi-level model to show how team composition differentially influences inexperienced team members' (rookies) and experienced team members' (veterans) knowledge sourcing. Team experience had little differential effect on veteran knowledge sourcing, except when the

team was very experienced; then veterans slowed or stopped their KR use. Rookies were more influenced by team composition: when working on teams with too little experience, too much experience, or a 
disparity of experience, rookie KR sourcing was limited. Yet on moderately experienced teams, rookies used almost on par with veterans. Thus the apex of the inverted-U relationship between team experience and knowledge sourcing represented the increased sourcing by rookies on moderately experienced teams.

Our results also demonstrate that people were influenced differently by their team's experience versus their team's familiarity. We found a significant effect only for team familiarity, not for individual familiarity. And we did not find a cross-level moderation effect between team familiarity and individual experience. All team members used more on familiar teams, and slightly slowed use on very familiar teams. These findings suggest that familiarity influences individual behavior through the group's shared social system, rather than through each individual's specific relationships. Reagan and McEvily (2003) similarly found that social cohesion - which is about overall network density rather than individual dyadic ties - increased "the willingness and motivation of individuals to invest time, energy, and effort in sharing knowledge with others" (pg. 240). We were surprised that familiarity did not differentially influence rookie team members, who we thought had more to gain from familiar teams. Future research could probe the specific mechanisms that encourage experienced team member's KR sourcing on familiar teams.

In contrast, team firm experience differentially influenced rookies, as described above. Experience is a property of the people in the team network (rather than a property of their ties, like familiarity). Our findings suggest that experience influences individual behavior through individual and group-level effects. As individuals gain firm experience, they develop information processing abilities, experiential understanding, confidence and comfort, and fluency in the technical language of the organization. But they are also involved in their group's relational dynamics (like status or specialization) based on their experience relative to others. Moreover, in their group people may think more or less like them based on their mutual experience at the firm. Thus experience - unlike familiarity - played out in different ways for different people at different levels of analysis (individual and group).

\subsection{Theoretical Implications}

These results complement and update prior research on individual experience and capabilities, 
team composition, and knowledge sourcing.

\section{Individual Experience and Capabilities}

Many theories focused on people's information technology (IT) use predict use based on people's experience and related capabilities (Agarwal \& Prasad, 2000; Carlson \& Zmud, 1999; Markus, 2001). Our results support the general trend predicted by this research - in every condition, experienced people used the KR more than inexperienced people. But we extend this research to show that the social system in which people are embedded influences their sourcing behavior beyond their individual experience and capability. Inexperienced team members used as much as experienced team members when the team conditions were right.

\section{Inverted-U Relationships in Team Composition}

In contrast to individual-level theories that associate more experience with more KR sourcing, team-level theories predict that teams source less as they gain experience. Our results also support this general trend - both very experienced and very familiar teams influenced individual team members such that, on average, they sourced less than people on moderately experienced teams. We advanced this research by testing the underlying patterns of individual KR sourcing that give rise to these curvilinear relationships. At the low end of team experience, rookies do not get the help they need. At the high end, veterans are most susceptible to experiential inertia and reducing their knowledge search. Inverted-U relationships have been documented in many settings, showing the risk of too much or too little of many states, traits, or experiences (Grant \& Schwartz, 2011). Our research shows differential individual-level effects of a team-level inverted-U relationship.

Our research also complements Katz' (1982) findings about the inverted-U relationship between team composition, knowledge sourcing, and performance by updating these for modern work teams that have fluid and globally distributed membership. Katz studied co-located, stable, research and development teams who worked together for years before their knowledge sourcing activities and performance declined. We found curvilinear effects for experience and familiarity in distributed teams who only worked together some months. Our effect sizes were smaller than those found by Katz, but the 
trend suggests a decreasing return to average team experience and familiarity even for fluid and distributed teams. These findings hold practical value for managers composing modern work teams. As Rentsch (1994) suggested: “Team managers might keep in mind potential team members' experience levels when making team assignments" (pg. 450). Perhaps counterintuitively, very experienced teams may not be the best performers, even among an inexperienced workforce in emerging markets. The inertial and status implications of working on highly experienced teams may limit sourcing behaviors of rookie team members. Future research could valuably explore the implications for learning and development.

Knowledge repository use as knowledge sourcing

We note an important contingent condition in our findings: our focus was specifically on sourcing from a knowledge repository. In some ways, this focus is a strength of the present study because it allowed us to use granular, objective data on individual and team knowledge sourcing. These unique data allowed us to consider a multi-level research question that had not been previously resolved. At the same time, KR use is a particular kind of knowledge sourcing, and the dynamics of IT use differs in important ways from interpersonal knowledge sourcing. Future research should also consider individual and team level experience and interpersonal knowledge sourcing.

\subsection{Managerial Implications}

We began the paper by noting a real practical problem faced by many global firms. $45 \%$ of the workforce we studied had less than 1 year of firm experience, and $75 \%$ had less than 1 year of prior work experience. During our site visit and interviews at Wipro, we heard about many programs focused on developing the knowledge base of this inexperienced workforce, including the KR system. The KR system was well-supported: the knowledge artifacts were vetted for quality, and the interface was designed to be navigable and user-friendly. Even so, the KR system was not widely used, particularly among rookies. Almost half of the workforce was inexperienced, and they were the least likely to take advantage of the knowledge stored in the KR.

Our study also provides a critical perspective on team composition for today's global firms, 
which deploy inexperienced workers onto teams with varying experience (Hackman \& Katz, 2010; Mortensen, 2010). For these teams to be effective, they and their managers must learn how to support coordination of work among inexperienced teammates. Without team-support, the KR did not overcome the limited capabilities of inexperienced workers. Only under certain conditions did rookies make use of this resource. But there is a delicate balance - stacking the team with experience can inhibit the rookies because of status issues of their relative inexperience or can inhibit use by all veteran team mates too.

\subsection{Limitations}

We note two additional limitations to our study. Although our data are archival and detailed, they did not capture which specific components were downloaded. This information could greatly enrich our understanding of the kinds of KR artifacts that are used, under what conditions, and how this influences performance. This limitation is not likely to bias our results in a systematic way (i.e., our hypotheses focus on amount of use rather than content of use), but it does prevent broader claims and understanding. Also, our analysis is of one KR in one organization. This setting allowed us to establish a baseline for the social conditions associated with KR sourcing, but as the conditions change, patterns of use may change as well (e.g., because of incentive programs, norms, or KR design (Bock, Kankanhalli, \& Sharma, 2006; Bock, Sabherwal, \& Qian, 2008; Markus, 2001)).

\subsection{Conclusion}

Advances in information and communication technologies allow firms to deploy IT solutions to strategic challenges like an inexperienced workforce. Our research shows that these kinds of solutions hold promise for performance, but like most organizational phenomena, require behavioral theories to explain how individuals and groups are likely to interact with the technologies and with each other around the technologies. 


\section{References}

Agarwal, R., \& Prasad, J. 2000. A field study of the adoption of software process innovations by information systems professionals. Ieee Transactions on Engineering Management, 47(3): 295308.

Alge, B. J., Wiethoff, C., \& Klein, H. J. 2003. When does the medium matter? Knowledge-building experiences and opportunities in decision-making teams. Organizational Behavior and Human Decision Processes, 91(1): 26-37.

Ancona, D. G., \& Caldwell, D. F. 1992. Bridging the Boundary - External Activity and Performance in Organizational Teams Administrative Science Quarterly, 37(4): 634-665.

Argote, L., Beckman, S. L., \& Epple, D. 1990. The persistence and transfer of learning in industrial settings. Management Science, 36(2): 140-154.

Balkundi, P., \& Harrison, D. A. 2006. Ties, leaders, and time in teams: Strong inference about network structure's effects on team viability and performance. Academy of Management Journal, 49(1): 49-68.

Banker, R. D., \& Kemerer, C. F. 1989. Scale economies in new software development. IEEE Transactions on Software Engineering, 15(10): 1199-1206.

Berman, S., Down, J., \& Hill, C. W. L. 2002. Tacit knowledge as a source of competitive advantge in the National Basketball Association. Academy of Management Journal, 45(1): 13-31.

Bock, G. W., Kankanhalli, A., \& Sharma, S. 2006. Are norms enough? The role of collaborative norms in promoting organizational knowledge seeking. European Journal of Information Systems, 15(4): 357-367.

Bock, G. W., Sabherwal, R., \& Qian, Z. J. 2008. The Effect of Social Context on the Success of Knowledge Repository Systems. Ieee Transactions on Engineering Management, 55(4): 536551.

Bock, G. W., Zmud, R. W., Kim, Y. G., \& Lee, J. N. 2005. Behavioral intention formation in knowledge sharing: Examining the roles of extrinsic motivators, social-psychological forces, and organizational climate. Mis Quarterly, 29(1): 87-111.

Boehm, B. 1981. Software Engineering Economics. New York: Prentice Hall.

Boh, W. F., Slaughter, S. A., \& Espinosa, J. A. 2007. Learning from experience in software development: A multilevel analysis. Management Science, 53(8): 1315-1331.

Bohn, R. 2005. From Art to Science in Manufacturing: The Evolution of Technological Knowledge. Foundations and Trends in Technology, Information, and Operations Management, 1(2): 182.

Borycki, E. M., Lemieux-Charles, L., Nagle, L., \& Eysenbach, G. 2009. Evaluating the Impact of Hybrid Electronic-paper Environments Upon Novice Nurse Information Seeking. Methods of Information in Medicine, 48(2): 137-143.

Carlson, J. R., \& Zmud, R. W. 1999. Channel expansion theory and the experiential nature of media richness perceptions. Academy of Management Journal, 42(2): 153-170.

Chi, N. W., Huang, Y. M., \& Lin, S. C. 2009. A Double-Edged Sword? Exploring the Curvilinear Relationship Between Organizational Tenure Diversity and Team Innovation: The Moderating Role of Team-Oriented HR Practices. Group \& Organization Management, 34(6): 698-726.

Davenport, T. H., \& Prusak, L. 1998. Working Knowledge: How Organizations Manage What They Know. Boston: Harvard Business School Press. 
Dutton, J. E., \& Thomas, M. A. 1984. Treating progress functions as a managerial opportunity. Academy of Management Review, 9(2): 235-247.

Edmondson, A. 1999. Psychological safety and learning behavior in work teams. Administrative Science Quarterly, 44(2): 350-383.

Espinosa, J. A., Slaughter, S. A., Kraut, R. E., \& Herbsleb, J. D. 2007. Familiarity, complexity, and team performance in geographically distributed software development. Organization Science, 18(4): 613-630.

Faraj, S., \& Sproull, L. 2000. Coordinating expertise in software development teams. Management Science, 46(12): 1554-1568.

Fishbein, M., \& Ajzen, I. 1975. Belief, Attitude, Intention, and Behavior: An Introduction to Theory and Research: Addison-Wesley.

Gardner, H. K., Gino, F., \& Staats, B. R. 2012. Dynamically integrating knowledge in teams: Transforming resources into performance. Academy of Management Journal, 55(4).

Gilson, L. L., Lim, H. S., Luciano, M. M., \& Choi, J. N. 2013. Unpacking the cross-level effects of tenure diversity, explicit knowledge, and knowledge sharing on individual creativity. Journal of Occupational and Organizational Psychology, 86(2): 203-222.

Gino, F., Argote, L., Miron-Spektor, E., \& Todorova, G. 2010. First, get your feet wet: The effects of learning from direct and indirect experience on team creativity. Organizational Behavior and Human Decision Processes, 111(2): 102-115.

Grant, A. M., \& Schwartz, B. 2011. Too Much of a Good Thing: The Challenge and Opportunity of the Inverted U. Perspectives on Psychological Science, 6(1): 61-76.

Grant, R. M. 1996. Toward a knowledge-based theory of the firm. Strategic Management Journal, 17: 109-122.

Gray, P. H., \& Durcikova, A. 2005. The role of knowledge repositories in technical support environments: Speed versus learning in user performance. Journal of Management Information Systems, 22(3): 159-190.

Gray, P. H., \& Meister, D. B. 2004. Knowledge sourcing effectiveness. Management Science, 50(6): 821-834.

Griffith, T. L., \& Neale, M. A. 2001. Information processing in traditional, hybrid, and virtual teams: From nascent knowledge to transactive memory, Research in Organizational Behavior, Vol 23, Vol. 23: 379-421. Amsterdam: Jai-Elsevier Sci Bv.

Haas, M. R., \& Hansen, M. T. 2007. Different knowledge, different benefits: Toward a productivity perspective on knowledge sharing in organizations. Strategic Management Journal, 28(11): 1133-1153.

Hackman, J. R. (Ed.). 1992. Group influences on individuals in organizations. Palo Alto: Consulting Psychologists Press.

Hackman, J. R., \& Katz, N. 2010. Group behavior and performance. In S. Fiske (Ed.), Handbook of Social Psychology, Vol. 5th ed. New York: Wiley.

Hansen, M. T., Nohria, N., \& Tierney, T. 1999. What's your strategy for managing knowledge? Harvard Business Review, 77(2): 106-+.

Hargadon, A. B., \& Bechky, B. A. 2006. When Collections of Creatives Become Creative Collectives: A Field Study of Problem Solving at Work. Organization Science, 17(4): 484-500.

Harrison, D. A., \& Klein, K. J. 2007. What's the difference? Diversity constructs as separation, variety, or disparity in organizations. Academy of Management Review, 32(4): 1199-1228. 
Hitt, M. A., Bierman, L., Uhlenbruck, K., \& Shimizu, K. 2006. The importance of resources in the internationalization of professional service firms: The good, the bad, and the ugly. Academy of Management Journal, 49(6): 1137-1157.

Hofmann, D. A., Lei, Z., \& Grant, A. M. 2009. Seeking help in the shadow of doubt: The sensemaking processes underlying how nurses decide whom to ask for advice. Journal of Applied Psychology, 94(5): 1261-1274.

Huber, G. P. 1991. Organizational Learning: The Contributing Processes and Literatures Organization Science, 2(1): 88-115.

Huber, G. P., \& Lewis, K. 2011. Cross-Understanding and Shared Social Theories. Academy of Management Review, 36(2): 422-424.

Huckman, R. S., \& Pisano, G. P. 2006. The firm specificity of individual performance: Evidence from cardiac surgery. Management Science, 52(4): 473-488.

Huckman, R. S., Staats, B. R., \& Upton, D. M. 2009. Team Familiarity, Role Experience, and Performance: Evidence from Indian Software Services. Management Science, 55(1): 85-100.

Jackson, C. L., \& LePine, J. A. 2003. Peer responses to a team's weakest link: A test and extension of LePine and van Dyne's model. Journal of Applied Psychology, 88(3): 459-475.

Katz, R. 1982. The Effects of Group Longevity on Project Communcation and Performance. Administrative Science Quarterly, 27(1): 81-104.

Katz, R., \& Allen, T. J. 1982. Investigating the Not Invented Here (NIH) syndrome: A look at the performance, tenure, and communication patterns of $50 \mathrm{R} \& \mathrm{D}$ project groups. $\boldsymbol{R} \& \boldsymbol{D}$ Management, 12(1): 7-20.

Katz, R., \& Tushman, M. 1979. Communication patterns, project performance, and task characteristics: An empirical evaluation and integration in an R\&D setting. Organizational Behavior and Human Performance, 23(2): 139-162.

Kc, D. S., \& Staats, B. 2012. Accumulating a portfolio of experience: The effect of focal and related experience on surgeon performance. Manufacturing \& Service Operations Management, 14(4): 618-633.

Khanna. 2013. India's IT/ITeS Industry. Paper presented at the OECD Knowledge-Based Capital Conference, Paris.

Kim, P. H. 1997. When what you know can hurt you: A study of experiential effects on group discussion and performance. Organizational Behavior and Human Decision Processes, 69(2): 165-177.

Klein, K., \& Kozlowski, S. 2000. From Micro to Meso: Critical Steps in Conceptualizing and Conducting Multilevel Research. Organizational Research Methods, 3(3): 211-236.

Klein, K. J., Bliese, P. D., Kozlowski, S. W., Dansereau, F., Gavin, M. B., \& Griffin, M. A. (Eds.). 2000. Multilevel analytical techniques: Commonalities, differences, and continuing questions.

Klein, K. J., Conn, A. B., Smith, D. B., \& Sorra, J. S. 2001. Is everyone in agreement? An exploration of within-group agreement in employee perceptions of the work environment. Journal of Applied Psychology, 86(1): 3-16.

Kozlowski, S. W. J., \& Klein, K. J. 2000. A multilevel approach to theory and research in organizations. In K. J. Klein, \& S. W. J. Kozlowski (Eds.), Multilevel Theory, Research, and Methods in Organizations: 3-90. San Francisco: Jossey-Bass.

Larson, J. R., Jr. 2010. In Search of Synergy in Small Group Performance. New York: Psychology Press. 
Levenson, A. 2012. Talent management: challenges of building cross-functional capability in highperformance work systems environments. Asia Pacific Journal of Human Resources, 50(2): 187-204.

Lewis, K., Lange, D., \& Gillis, L. 2005. Transactive Memory Systems, learning, and learning transfer. Organization Science, 16(6): 581-598.

MacCormack, A., Verganti, R., \& Iansiti, M. 2001. Developing products on "Internet time": The anatomy of a flexible development process. Management Science, 47(1): 133-150.

Markus, M. L. 2001. Toward a Theory of Knowledge Reuse: Types of Knowledge Reuse Situations and Factors in Reuse Success. Journal of Management Information Systems, 18(1): 57-93.

Mathieu, J. E., Maynard, M. T., Rapp, T., \& Gilson, L. L. 2008. Team effectiveness 1997-2007: A review of recent advancements and a glimpse into the future. Journal of Management, 34(3): 410-476.

Mortensen, M. 2010. From Teams to Recombinant Collaboration: Understanding the Evolution of Organizational Work. Working Paper: Sloan School of Management, Massachusetts Institute of Technology.

Narayanan, S., Balasubramanian, S., \& Swaminathan, J. M. 2009. A Matter of Balance: Specialization, Task Variety, and Individual Learning in a Software Maintenance Environment. Management Science, 55(11): 1861-1876.

Nonaka, I. 1994. A Dynamic Theory of Organizational Knowledge Creation. Organization Science, 5(1): 14-37.

O'Reilly, C., Caldwell, D. F., \& Barnett, W. P. 1989. Work Group Demography, Social Integration, and Turnover. Administrative Science Quarterly, 34: 21-37.

Okhuysen, G. A. 2001. Structuring change: Familiarity and formal interventions in problem-solving groups. Academy of Management Journal, 44(4): 794-808.

Ready, D. A., Hill, L. A., \& Conger, J. A. 2008. Winning the Race for Talent in Emerging Markets. Harvard Business Review, 86(11): 63-+.

Reagans, R., Argote, L., \& Brooks, D. 2005. Individual experience and experience working together: Predicting learning rates from knowing who knows what and knowing how to work together. Management Science, 51(6): 869-881.

Rentsch, J. R., Heffner, T. S., \& Duffy, L. T. 1994. What you know is what you get from experience: Team experience related to teamwork schemas Group \& Organization Management, 19(4): 450474.

Rentsch, J. R., \& Klimoski, R. J. 2001. Why do 'great minds' think alike?: antecedents of team member schema agreement. Journal of Organizational Behavior, 22: 107-120.

Rollag, K. 2004. The impact of relative tenure on newcomer socialization dynamics. Journal of Organizational Behavior, 25(7): 853-872.

Salas, E., Cooke, N. J., \& Rosen, M. A. 2008. On teams, teamwork, and team performance: Discoveries and developments. Human Factors, 50(3): 540-547.

Singh, J., Hansen, M. T., \& Podolny, J. M. 2010. The World Is Not Small for Everyone: Inequity in Searching for Knowledge in Organizations. Management Science, 56(9): 1415-1438.

Spender, J. C. 1996. Making knowledge the basis of a dynamic theory of the firm. Strategic Management Journal, 17: 45-62.

Staats, B. R. 2012. Unpacking Team Familiarity: The Effects of Geographic Location and Hierarchical Role. Production and Operations Management, 21(3): 619-635. 
Staats, B. R., \& Gino, F. 2012. Specialization and Variety in Repetitive Tasks: Evidence from a Japanese Bank. Management Science, 58(6): 1141-1159.

StataCorp. 2013. Stata Statistical Software: Release 13. College Station, TX: StataCorp LP.

Stein, E. W., \& Zwass, V. 1995. Actualizing organizational memory with information systems. Information Systems Research, 6(2): 85-117.

Sutcliffe, A. G., Ennis, M., \& Watkinson, S. J. 2000. Empirical studies of end-user information searching. Journal of the American Society for Information Science, 51(13): 1211-1231.

Thomas-Hunt, M. C., Ogden, T. Y., \& Neale, M. A. 2003. Who's really sharing? Effects of social and expert status on knowledge exchange within groups. Management Science, 49(4): 464-477.

Van der Vegt, G. S., Bunderson, J. S., \& Oosterhof, A. 2006. Expertness diversity and interpersonal helping in teams: Why those who need the most help end up getting the least. Academy of Management Journal, 49(5): 877-893.

Vroom, V. H. 1964. Work and motivation. Oxford, England: Wiley.

Wegner, D. M. 1987. Transactive memory: A contemporary analysis of the group mind. In G. Mullen, \& G. Goethals (Eds.), Theories of Group Behavior: 185-208. New York: Springer-Verlag.

Woolley, A. W., Chabris, C. F., Pentland, A., Hashmi, N., \& Malone, T. W. 2010. Evidence for a Collective Intelligence Factor in the Performance of Human Groups. Science, 330(6004): 686688.

Zhang, Z. X., Hempel, P. S., Han, Y. L., \& Tjosvold, D. 2007. Transactive memory system links work team characteristics and performance. Journal of Applied Psychology, 92(6): 1722-1730. 


\section{Figures and Tables}

Figure 1. Conceptual Model and Results

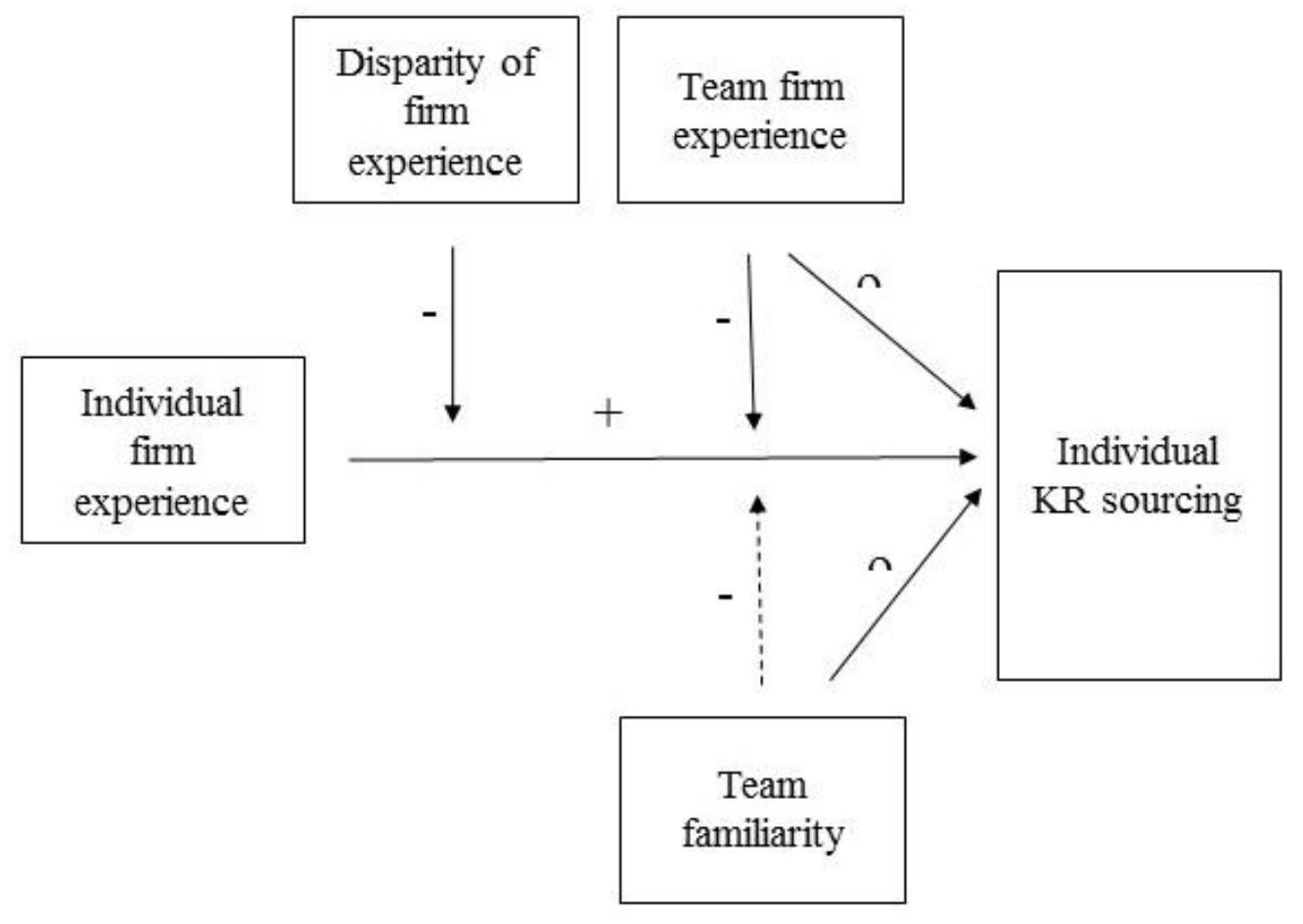

\section{Figure 1. Legend}

Solid arrow indicates confirmed hypothesis

Dotted arrow indicates unconfirmed hypothesis

$\checkmark$ represents that an inverted-U relationship 
Table 1. Summary statistics and correlation table of variables in the individual KR sourcing models $(n=13,470)$

\begin{tabular}{|c|c|c|c|c|c|c|c|c|c|c|c|c|c|c|c|}
\hline & Variable & Mean & $\sigma$ & 1 & 2 & 3 & 4 & 5 & 6 & 7 & 8 & 9 & 10 & 11 & 12 \\
\hline 1. & Individual KR Sourcing & 0.47 & 0.88 & & & & & & & & & & & & \\
\hline 2. & Individual Firm Experience ${ }^{\mathrm{a}}$ & 1.95 & 2.36 & 0.05 & & & & & & & & & & & \\
\hline 3. & Team Firm Experience ${ }^{a}$ & 1.95 & 0.74 & 0.02 & 0.31 & & & & & & & & & & \\
\hline 4. & Team Familiarity ${ }^{\mathrm{a}}$ & 0.29 & 0.70 & 0.04 & 0.10 & 0.33 & & & & & & & & & \\
\hline 5. & Disparity in Team Experience ${ }^{a}$ & 0.08 & 0.08 & 0.02 & -0.02 & -0.07 & -0.06 & & & & & & & & \\
\hline 6. & Individual Team Familiarity & 0.29 & 0.78 & 0.02 & 0.13 & -0.07 & -0.05 & 0.07 & & & & & & & \\
\hline 7. & Individual Prior Work Experience & 1.39 & 2.39 & 0.04 & 0.16 & 0.28 & 0.82 & -0.06 & -0.04 & & & & & & \\
\hline 8. & Project Scale & 3.32 & 1.98 & 0.07 & -0.05 & -0.15 & -0.08 & -0.06 & -0.05 & -0.08 & & & & & \\
\hline 9. & Estimated Effort & 9.38 & 1.17 & 0.1 & -0.11 & -0.36 & -0.17 & -0.28 & 0.02 & -0.14 & 0.32 & & & & \\
\hline 10. & Estimated Duration & 5.63 & 0.62 & 0.08 & -0.12 & -0.39 & -0.18 & -0.10 & 0.00 & -0.14 & 0.26 & 0.65 & & & \\
\hline 11. & Team Size & 3.71 & 0.82 & -0.04 & -0.04 & -0.14 & -0.09 & -0.79 & -0.08 & -0.06 & 0.11 & 0.42 & 0.25 & & \\
\hline 12. & Offshore Percentage & 0.86 & 0.14 & 0.02 & 0.00 & 0.01 & -0.05 & 0.07 & -0.09 & -0.03 & 0.00 & -0.14 & -0.04 & -0.06 & \\
\hline 13. & Contract Type & 0.41 & 0.49 & -0.02 & 0.00 & 0.00 & $\mathbf{- 0 . 0 7}$ & 0.18 & 0.08 & -0.07 & -0.02 & 0.03 & -0.02 & -0.26 & 0.04 \\
\hline
\end{tabular}

Note. Bold denotes significance of less than $5 \%$.

${ }^{a}$ In models this variable is centered by subtracting the mean. Values here are before centering. 
Table 2. Summary results of the regression of individual KR sourcing $(n=13,470)$

Dependent Variable: Individual KR Sourcing

(1)

Model:

Individual Firm Experience

Team Firm Experience

Team Firm Experience Squared

Team Familiarity

Team Familiarity Squared

Disparity in Team Experience

Individual Team Familiarity

Individual Prior Work

Experience

Individual Firm Experience $\times$

Team Firm Experience

Individual Firm Experience $x$

Team Familiarity

Individual Firm Experience $x$

Disparity in Team Firm Exp

Project Scale

Estimated Effort

Estimated Duration

Team Size

Offshore Percentage

Contract Type

Constant

Log-Likelihood

Wald chi-squared

Notes. $+,{ }^{*}, * *$ and $* * *$ denote signficance at the $10 \%, 5 \%, 1 \%$ and $0.1 \%$ levels, respectively. All models

include, but results are not shown for, the following variables: number of languages, software language, and number of technologies.

(2)

(3)

Interactions

$0.1173 * * * \quad 0.1418 * * *$

$(0.0000) \quad(0.0000)$

$0.4125^{*} \quad 0.3550 *$

$(0.0109) \quad(0.0295)$

$-0.3109 * * * \quad-0.2272 *$

(0.0003) (0.0107)

$1.3356^{* * *} \quad 1.3322 * * *$

(0.0000) (0.0000)

$-0.2397 * * * \quad-0.2394 * * *$

(0.0002) (0.0002)

$-0.1626 \quad 0.0214$

$(0.9189) \quad(0.9893)$

$0.0532 \quad 0.0621$

$(0.6328) \quad(0.5853)$

$0.0676 * * \quad 0.0660 * *$

$\begin{array}{ll}0.0011) & (0.0014)\end{array}$

$-0.0841^{* *}$

(0.0010)

0.0038

(0.8980)

$0.4807+$

(0.0549)

$0.1648 * *$

(0.0015)

$0.7356 * * * \quad 0.7709 * * * \quad 0.7680 * * *$

$\begin{array}{lll}(0.1414) & (0.0000) & (0.0000)\end{array}$

$\begin{array}{lll}0.2401 & 0.4316^{*} & 0.4263^{*}\end{array}$

$\begin{array}{lll}(0.2098) & (0.0352) & (0.0376)\end{array}$

$0.9604 * * * \quad-0.9239 * * * \quad-0.9047 * * *$

$\begin{array}{lll}(0.1556) & (0.0000) & (0.0001)\end{array}$

$\begin{array}{lll}0.8952 & 1.4719 * & 1.4757 *\end{array}$

$\begin{array}{lll}(0.7070) & (0.0321) & (0.0317)\end{array}$

$\begin{array}{lll}-0.3602 & -0.3936+ & -0.3931+\end{array}$

$\begin{array}{lll}(0.2195) & (0.0634) & (0.0639)\end{array}$

$-3.8974 * * \quad-5.7054 * * * \quad-5.7181 * * *$

$\begin{array}{lll}(1.2353) & (0.0000) & (0.0000)\end{array}$

$\begin{array}{lll}-42,177.0 & -42131.1 & -42,124.0\end{array}$

95.4*** 197.3*** 212.0***


Figure 2. Cross-level Moderation Effects in Predicting Individual Knowledge Repository (KR) Use

Fig 2a. Team Firm Experience and Individual Firm Experience

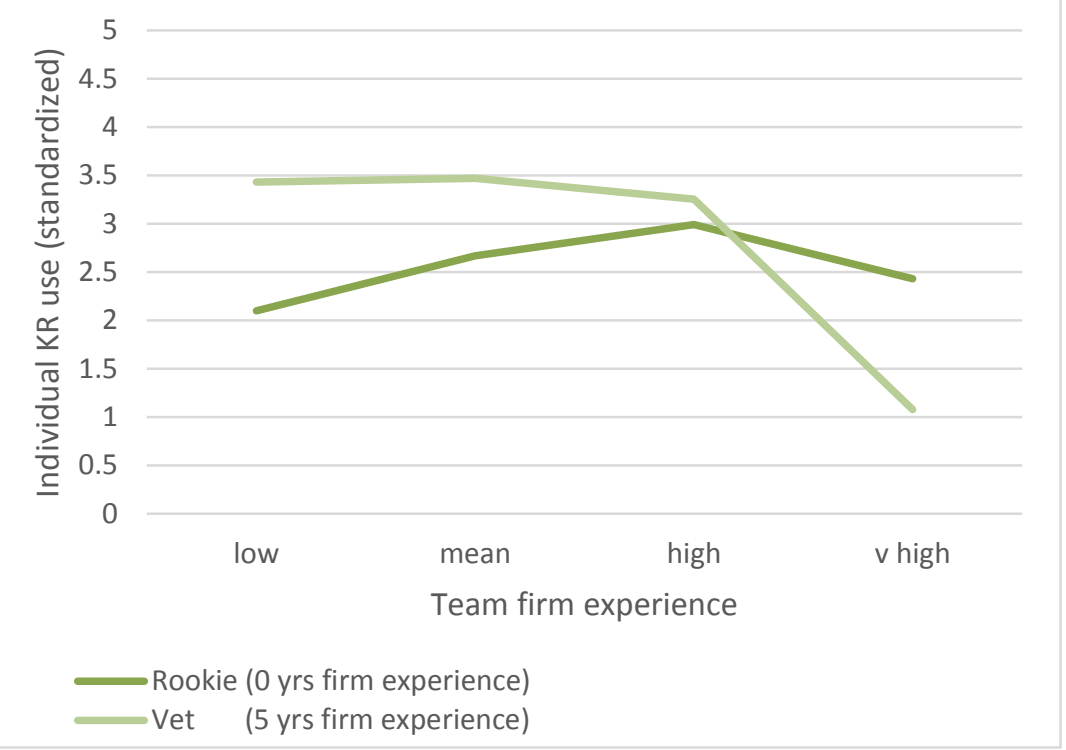

Fig 2b. Team Familiarity and Individual Firm Experience

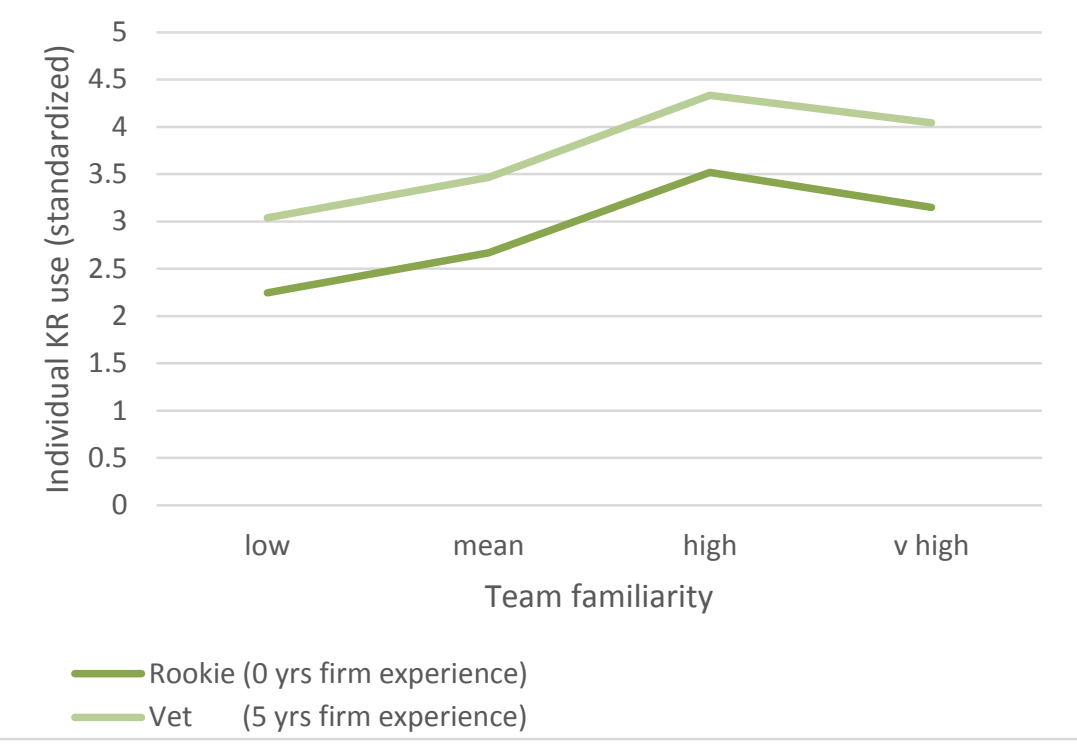

Fig 2c. Disparity of Team Firm Experience and Individual Firm Experience

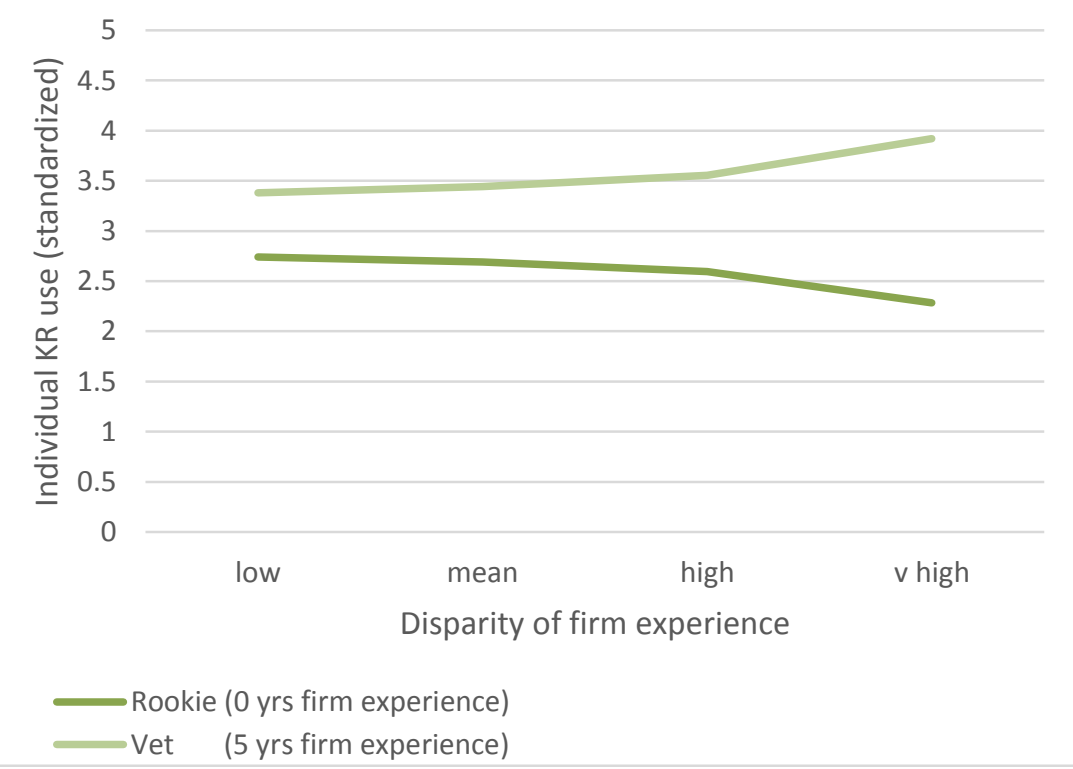


Table 3. Summary results of the regression of team performance $(n=330)$

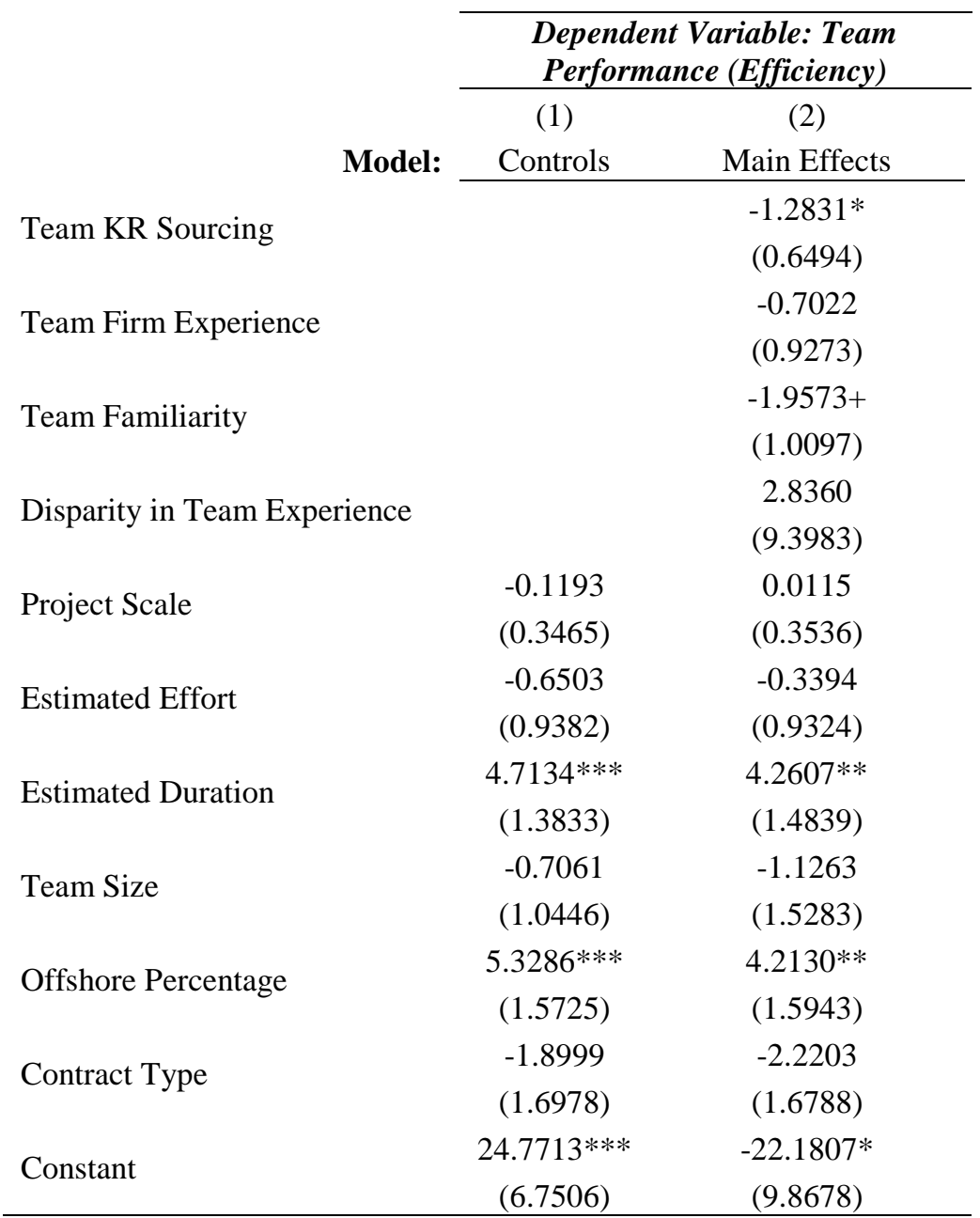

Notes. $+, *, * *$ and $* * *$ denote signficance at the $10 \%, 5 \%, 1 \%$ and $0.1 \%$ levels,

respectively. All models include, but results are not shown for the following variables: number of languages, software language, and number of technologies. Model includes customer fixed effects to control for account-invariant differences across projects. With this control, the final sample is 330 projects. 


\section{Reviewers' Appendix}

Table 1. Summary results of the regression of individual KR sourcing $(n=13,470)$

\section{Dependent Variable: Individual KR Sourcing}

(1)

(2)

(3)

\section{Model:}

Controls

Individual Firm Experience

Main Effects

Interactions

Team Firm Experience

Team Firm Experience Squared

Team Familiarity

Team Familiarity Squared

Disparity in Team Experience

Individual Team Familiarity

Individual Prior Work

Experience

Individual Firm Experience $x$

Team Firm Experience

Individual Firm Experience $x$

Team Familiarity

Individual Firm Experience $x$

Disparity in Team Firm Exp

Project Scale

Estimated Effort

Estimated Duration

Team Size

Offshore Percentage

Contract Type

Constant

$0.1567 * *$

(0.0542)

$0.7210 * * *$

(0.1408)

0.2448

(0.2098)

$0.9596 * * *$

(0.1559)

$0.7741 * * *$

(0.1512)

$-0.3540$

(0.2199)

3.7048***

(1.0321)

$-42497.9$

$119.6^{* * *}$

Wald chi-squared

Notes. $+{ }^{*}, * *$ and $* * *$ denote signficance at the $10 \%, 5 \%, 1 \%$ and $0.1 \%$ levels, respectively. All models

include, but results are not shown for the following variables: number of languages, software language, and number of technologies.
These models are the same as Table 2 in the main paper; the one difference is in how the offshore variable is calculated. In Table 2 , the offshore variable was calculated as the percentage of hours that were completed by the team at the Indian facilities, divided by the total number of hours worked by the team. In Reviewers' Appendix, Table 1, the offshore variable was calculated as the number of team members in each location. 


\section{Reviewers' Appendix}

Table 2. Summary results of the regression of individual KR sourcing $(n=13,470)$

\begin{tabular}{|c|c|c|c|}
\hline \multirow[b]{3}{*}{ Model: } & \multicolumn{3}{|c|}{ Dependent Variable: Individual KR Sourcing } \\
\hline & (1) & (2) & (3) \\
\hline & Controls & Main Effects & Interactions \\
\hline Individual Firm Experience & & $\begin{array}{c}0.1172^{* * * *} \\
(0.0000)\end{array}$ & $\begin{array}{c}0.1417 * * * \\
(0.0000)\end{array}$ \\
\hline Team Firm Experience & & $\begin{array}{c}0.4452 * * \\
(0.0053)\end{array}$ & $\begin{array}{l}0.3884 * \\
(0.0156)\end{array}$ \\
\hline Team Firm Experience Squared & & $\begin{array}{c}-0.2840 * * * \\
(0.0010)\end{array}$ & $\begin{array}{l}-0.2001 * \\
(0.0258)\end{array}$ \\
\hline Team Familiarity & & $\begin{array}{c}1.3197 * * * \\
(0.0000)\end{array}$ & $\begin{array}{c}1.3177 * * * \\
(0.0000)\end{array}$ \\
\hline Team Familiarity Squared & & $\begin{array}{c}-0.2241 * * * \\
(0.0005)\end{array}$ & $\begin{array}{c}-0.2238 * * * \\
(0.0006)\end{array}$ \\
\hline Disparity in Team Experience & & $\begin{array}{c}0.2290 \\
(0.8858)\end{array}$ & $\begin{array}{c}0.4255 \\
(0.7901)\end{array}$ \\
\hline Individual Team Familiarity & & $\begin{array}{c}0.0638 \\
(0.5676)\end{array}$ & $\begin{array}{c}0.0727 \\
(0.5233)\end{array}$ \\
\hline Individual Prior Work & & $0.0664 * *$ & $0.0648 * *$ \\
\hline Experience & & $(0.0013)$ & $(0.0017)$ \\
\hline $\begin{array}{l}\text { Individual Firm Experience } \times \\
\text { Team Firm Experience }\end{array}$ & & & $\begin{array}{c}-0.0841 * * \\
(0.0010)\end{array}$ \\
\hline $\begin{array}{l}\text { Individual Firm Experience } \times \\
\text { Team Familiarity }\end{array}$ & & & $\begin{array}{c}0.0036 \\
(0.9034)\end{array}$ \\
\hline $\begin{array}{l}\text { Individual Firm Experience } \times \\
\text { Disparity in Team Firm Exp }\end{array}$ & & & $\begin{array}{l}0.4783+ \\
(0.0562)\end{array}$ \\
\hline Project Scale & $\begin{array}{c}0.1525^{* *} \\
(0.0551)\end{array}$ & $\begin{array}{c}0.1501^{* *} \\
(0.0045)\end{array}$ & $\begin{array}{c}0.1509 * * \\
(0.0043)\end{array}$ \\
\hline Estimated Effort & $\begin{array}{c}0.6542 * * * \\
(0.1404)\end{array}$ & $\begin{array}{c}0.7335^{* * *} \\
(0.0000)\end{array}$ & $\begin{array}{c}0.7296 * * * \\
(0.0000)\end{array}$ \\
\hline Estimated Duration & $\begin{array}{c}0.2714 \\
(0.2113)\end{array}$ & $\begin{array}{l}0.4570 * \\
(0.0261)\end{array}$ & $\begin{array}{l}0.4522 * \\
(0.0277)\end{array}$ \\
\hline Team Size & $\begin{array}{c}0.8134 * * * \\
(0.1517)\end{array}$ & $\begin{array}{c}-0.7754 * * * \\
(0.0005)\end{array}$ & $\begin{array}{c}-0.7536 * * * \\
(0.0007)\end{array}$ \\
\hline Offshore Percentage & $\begin{array}{c}1.1096 \\
(0.6941)\end{array}$ & $\begin{array}{l}1.6411 * \\
(0.0147)\end{array}$ & $\begin{array}{l}1.6421 * \\
(0.0147)\end{array}$ \\
\hline Contract Type & $\begin{array}{c}-0.5103 * \\
(0.2081)\end{array}$ & $\begin{array}{c}-0.4946^{*} \\
(0.0139)\end{array}$ & $\begin{array}{c}-0.4937 * \\
(0.0141)\end{array}$ \\
\hline Constant & $\begin{array}{c}-3.8855^{* *} \\
(1.2249)\end{array}$ & $\begin{array}{c}-6.0774 * * * \\
(0.0000)\end{array}$ & $\begin{array}{c}-6.0930 * * * \\
(0.0000)\end{array}$ \\
\hline Log-Likelihood & 42183.7 & -42137.7 & -42130.6 \\
\hline Wald chi-squared & $91.5 * * *$ & $194.1 * * *$ & $208.2 * * *$ \\
\hline
\end{tabular}

These models are also the same as Table 2 in the main paper; here, the difference is that customer fixed effects were not included. 